\title{
ChemComm
}

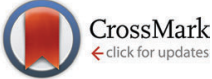

Cite this: Chem. Commun., 2016, 52, 9129

Received 18th January 2016 , Accepted 24th March 2016

DOI: $10.1039 / \mathrm{c} 6 \mathrm{cc00499g}$

www.rsc.org/chemcomm

\section{Selective partial hydrogenation of alkynes to (Z)-alkenes with ionic liquid-doped nickel nanocatalysts at near ambient conditions $\dagger$}

\author{
Hannelore Konnerth and Martin H. G. Precht।*
}

\begin{abstract}
A selective hydrogenation method for forming (Z)-alkenes from alkynes has been developed using a catalyst system of cheap Ni-NPs in a nitrile functionalised imidazolium based ionic liquid (IL) operating under very mild reaction conditions of $30-50{ }^{\circ} \mathrm{C}$ and 1-4 bar $\mathrm{H}_{2}$ pressure.
\end{abstract}

The hydrogenation of alkynes to produce selectively $(E)$ - or $(Z)$-alkenes is desirable as this reaction is a useful synthetic tool for the production of many bioactive natural products or pheromones. ${ }^{1-4}$ The synthesis of stilbene derivatives is especially interesting as these structural motifs are present in many relevant natural products currently under investigation in pharmacological studies. ${ }^{5-7}$ Many of these alkyne transformations to (Z)-alkenes make use of the famous Lindlar catalyst, consisting of $\mathrm{Pd}-\mathrm{CaCO}_{3}$ partially poisoned with $\mathrm{Pb}(\mathrm{OAc})_{2}$ and quinoline. ${ }^{8}$ Various heterogeneous catalyst systems are also known which make use of noble metals like Pd, Pt or Au. ${ }^{9-14}$ An approach towards more abundant and low-cost metals, thus expanding the applicability of this synthetic strategy, would be beneficial. Efforts have been made to investigate homogeneous nickel catalysts which make use of hydrogen transfer agents like $\mathrm{H}_{3} \mathrm{PO}_{2}$ or $\mathrm{HCO}_{2} \mathrm{H}$. These systems are either limited to internal alkynes to produce $(E)$-alkenes or require high reaction conditions. ${ }^{15,16}$ In 1981 a nickel on graphite catalyst was introduced which operates under mild reaction conditions; sensitivity towards oxidation prohibits reusability. ${ }^{17}$ Moreover, only a few nanoscale catalyst systems were reported using non-noble metals such as the binary $\mathrm{GaNi}^{18}$ or ternary $\mathrm{CuFeNi}^{19}$ system. Ni(0)-NPs, in combination with an alcohol as hydrogen source, have also been described, although stoichiometric amounts of an alkali metal and catalyst are needed. ${ }^{20}$ A nickel phosphide catalyst has also been reported, however the activity is low applied to diphenyl acetylene derivatives. ${ }^{21}$

In the field of catalysis, the use of metal catalysts in ionic liquids is of tremendous importance..$^{22-24}$ Besides, the role as "greener" solvents, ILs also show remarkable properties as

Department of Chemistry, Institute of Inorganic Chemistry, University of Cologne, Greinstraße 6, 50939 Cologne, Germany.E-mail: martin.prechtl@uni-koeln.de; Web: http://catalysis.uni-koeln.de; Fax: +492214701788

$\dagger$ Electronic supplementary information (ESI) available. See DOI: 10.1039/c6cc00499g reducing agents to synthesis nanoparticles and they act as stabilising agents for these NPs. ${ }^{25,26}$ Special properties including low vapour pressure, and high thermal and chemical stability make ILs suitable for the use in liquid-liquid biphasic systems, enabling facile separation of the catalyst from the substrate phase. Moreover, the selectivity of a metal-catalysed reaction can be controlled by steric or electronic properties of either the cationic or anionic component of the ionic liquid, which interacts with the nanoparticle surface or the substrate. This multi-functionality promotes the use of ionic liquids which combines reducing agent, stabilising agent, solvent and ligand as selectivity controller in one single compound in the catalyst phase. As described in our previous works, the ionic liquid plays a crucial role for the chemoselectivity in the hydrogenation of alkynes to $(Z)$-alkenes. ${ }^{12,27}$ Nitrile-functionalised imidazolium based ionic liquids are especially suitable to tune the selectivity towards partial hydrogenation. Pd-NPs embedded in IL showed a tunable selectivity for the production of either the corresponding (Z)-alkenes or alkanes in the hydrogenation of both terminal and internal alkynes under very mild reaction conditions. ${ }^{12}$ Moreover, a system with Fe-NPs in the same ionic liquid also showed the conversion of a wide substrate scope of internal alkynes to the corresponding $(Z)$-alkenes; harsh reaction conditions were required however $\left(80{ }^{\circ} \mathrm{C}, 60\right.$ bar $\mathrm{H}_{2}$ ). For the catalyst preparation, a strong reducing agent is necessary to form the active iron species in an organic solvent followed by extraction of the Fe-NPs into the IL; the procedure has to be carried out under strict absence of moisture and air to prevent oxidation of the sensitive catalyst. ${ }^{27}$

In order to recreate the advantages of noble metal catalysts whilst taking advantage of the benefits of abundant metals, we were interested in developing a catalyst system containing a cheap and abundant metal such as nickel, which is not as sensitive to oxidation as iron. We thus developed a Ni-NPs catalyst system, which operates under very mild reaction conditions, to hydrogenate internal and even terminal phenylalkynes to the corresponding (Z)-alkenes with high selectivity using molecular hydrogen (Scheme 1).

In a first step using diphenylacetylene as model substrate, an IL screening and optimisation of the reaction conditions towards a high selectivity for the $(Z)$-alkene was investigated. 


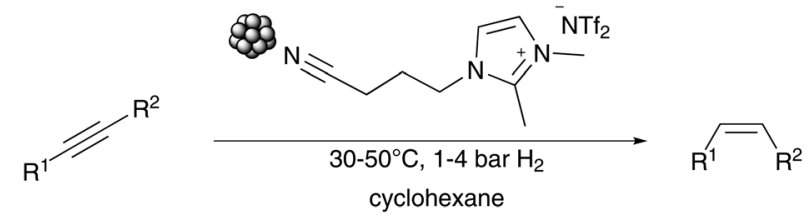

$\mathrm{R}=$ phenyl, alkyl, $\mathrm{H} \quad \mathrm{O} \mathrm{Ni}$

Scheme 1 Semihydrogenation of alkynes using Ni-NPs in nitrile functionalised IL.

The NPs were synthesised using different ionic liquids, through modification to known literature protocols, for the formation of Ni-NPs in imidazolium based ILs. ${ }^{25,28-30}$ The reactivity of all samples was seen to be high using mild reaction conditions of $30{ }^{\circ} \mathrm{C}$ within $6-16 \mathrm{~h}$ reaction times (Table 1 ). In all reactions, an excellent stereoselectivity for the formation of the $(Z)$-isomer was apparent, in several cases however, hydrogenation to the corresponding alkane occurred (Table 1; entries 1-3). The quantitative Ni-NP catalysed hydrogenation of diphenylacetylene is already apparent after only $6 \mathrm{~h}$ when using the non-functionalised

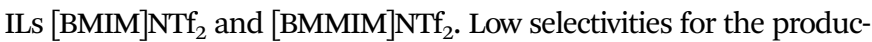
tion of the alkene relative to overreduction to the alkane are seen however (Table 1, entries 1 and 2). With the IL $\left[\mathrm{C}_{10}{\mathrm{MMIM}] \mathrm{NTf}_{2}}\right.$ (Table 1, entry 3) even a higher amount of alkane was produced with $83 \%$ yield. Compared to the imidazolium based ionic liquids bearing a butyl side chain, which result in Ni-NPs size of 7.8-8.2 nm, the NPs synthesised in the IL with the decyl side chain are much smaller with around $4.4 \mathrm{~nm}$ in diameter. Aside from the different size and shape of the formed NPs in different ILs, it is possible that the surrounding of the NPs by the IL itself influences the metal-surface interaction with the stabilizer and thus the outcome of this hydrogenation reaction. The longer hydrophobic alkylchain might increase the non-polar region around the nanoparticle surface and allows the less polar alkene,

Table 1 Optimisation reactions with different ionic liquids

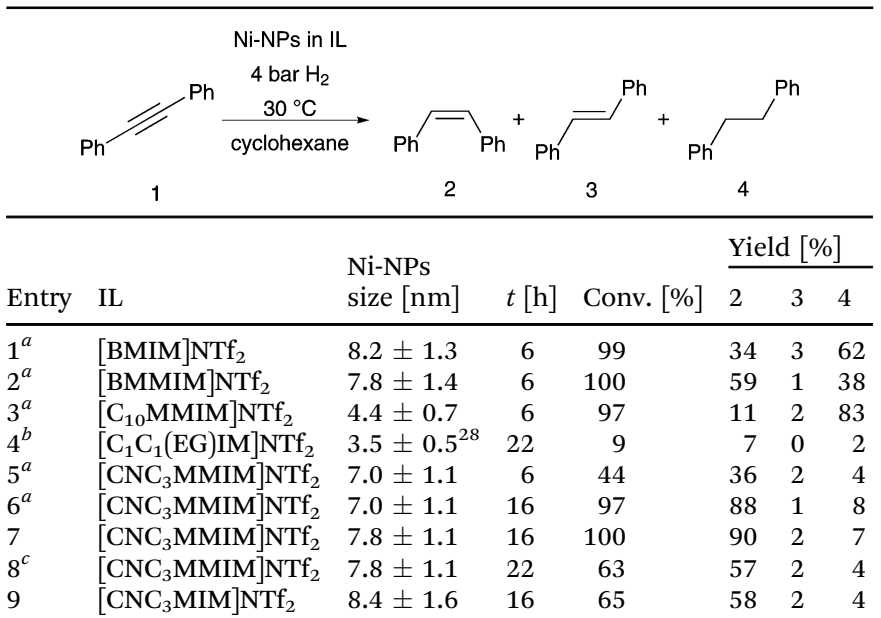

The volume of cyclohexane was $1 \mathrm{ml}$ in all reactions. ${ }^{a}$ For the synthesis of the NPs $0.3 \mathrm{~g}$ IL was used, the other reactions were conducted with $0.15 \mathrm{~g}$ IL. ${ }^{b}$ The synthesis of Ni-NPs was conducted accordingly to literature method. ${ }^{28}{ }^{c}$ The hydrogenation reaction was conducted with a constant pressure of 1 bar $\mathrm{H}_{2}$. compared to alkyne, a better accessibility for close proximity to the surface. The solubility of the alkene in the catalyst phase could also be enhanced, this might lead to an increase of hydrogenation activity resulting in production of the alkane. In the alkyl sidechain functionalised ILs (Table 1, entries 4-9), longer reaction times of $16 \mathrm{~h}$ are needed for quantitative conversion of the alkyne, although in the dihydroxyl functionalised IL only $10 \%$ conversion was achieved after $16.5 \mathrm{~h}$. Moreover, in all functionalised ILs the selectivity for the formation of the alkene is very high. These two results indicate a different coordination mode of the ILs on the Ni-NPs. As reported previously for nitrile-ILs, a coordination on the nanoparticle surface is suggested which involves the nitrilegroup. ${ }^{12,26,27}$ A higher coordination tendency further impedes displacement with the substrate, and thus a longer reaction time is necessary. Steric factors might also shield the surface of the nanoparticle or electronic modifications by the stabilizer, which might change the absorption/desorption mode of the more electron-rich alkyne-moiety. ${ }^{31,32}$ In the case of the diolfunctionalised IL drawing of conclusions is difficult due to the low conversion. A decomposition route of $\left[\mathrm{Ni}(\mathrm{COD})_{2}\right]$ in $\left[\mathrm{C}_{1} \mathrm{C}_{1}(\mathrm{EG}) \mathrm{IM}\right] \mathrm{NTf}_{2}$-IL is proposed via the formation of transitory non-classical NHC-ligands, confirmed by the generation of 1,3-COD, rather than a decomposition by simple ligand exchange of the OH-groups on the surface of the Ni-NPs. ${ }^{28}$ Thus, the diolfunctionality might simply create a very hydrophilic area around the nanoparticle surface in the hydrogenation reaction of the alkyne. In such an environment it would be difficult for the lipophilic substrates to get in close proximity to the nanoparticle surface. In the IL $\left[\mathrm{CNC}_{3} \mathrm{MIM}\right] \mathrm{NTf}_{2}$ a decreased conversion was observed, which is in accordance with the previously reported Fe-NPs-catalysed reaction in the same ionic liquid. ${ }^{27}$ Here, a

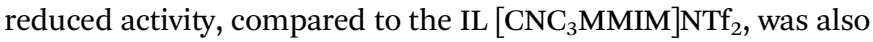
observed for the hydrogenation of diphenylacetylene. In this case the generation of NHC-complexes might be involved, although the selectivity for the alkene is still very high with about 93\% (Table 1, entry 9). In all investigated systems with different ILs the formed NPs have a similar shape and a size of about 7-8 nm, except the NPs which were synthesised in $\left[\mathrm{C}_{10} \mathrm{MMIM} \mathrm{NTf}_{2}\right.$ and $\left[\mathrm{C}_{1} \mathrm{C}_{1}(\mathrm{EG}) \mathrm{IM}\right] \mathrm{NTf}_{2}$, which have a size of about $4 \mathrm{~nm}$. Comparing only the systems with a similar size and shape, changes in activity and selectivity are obvious, which appear to be especially influenced by the respective ionic liquid.

Best results were achieved with $\left[\mathrm{CNC}_{3} \mathrm{MMIM}\right] \mathrm{NTf}_{2}$ at 4 bar $\mathrm{H}_{2}$ at $30{ }^{\circ} \mathrm{C}$ as quantitative conversion was achieved after $16 \mathrm{~h}$ with high selectivity for $(Z)$-stilbene (Table 1 , entry 7 ). Even a smaller amount of ionic liquid could be applied without loss of activity and selectivity; this makes its use in large scale even more attractive due to reduced costs (Table 1, entries 6 and 7). Interestingly, neither the synthesis of the Ni-NPs nor the hydrogenation conditions of diphenylacetylene (Table 1, entry 7 ) showed modification of the ionic liquid, which was confirmed by ${ }^{1} \mathrm{H},{ }^{13} \mathrm{C}$ or ${ }^{19} \mathrm{~F}-\mathrm{NMR}$ spectroscopy (see ESI $\dagger$ ). Only small amounts of cyclooctadiene were visible in the spectra after the decomposition of the $\left[\mathrm{Ni}(\mathrm{COD})_{2}\right]$ precursor. This is in vast contrast to iron and ruthenium NPs in such ILs, ${ }^{26,27}$ and underlines the suitability of this IL with Ni-NPs under the applied reaction conditions. 
Test reactions without Ni-catalyst or without applied hydrogen pressure under an atmosphere of argon yielded in no conversion (see $\mathrm{ESI} \dagger$ ); this confirms the crucial role of nickel as the active catalyst. Furthermore, we tested the reaction in [BMMIM] $\mathrm{NTf}_{2}$ with acetonitrile as additive. The nitrile group might coordinate as a ligand on the NP surface, similar to the coordination mode suggested for the nitrile functionalised IL. Indeed, in the hydrogenation reaction of diphenylacetylene, quantitative conversion resulted in $90 \%(Z)$-stilbene, which confirms the results of the IL screening that the functionalised side chain of the IL is responsible for the high chemoselectivity in this hydrogenation reaction.

We concentrated our investigation to evaluate the optimized catalyst system in the hydrogenation of diphenylacetylene to $(Z)$-stilbene, using $\left[\mathrm{Ni}(\mathrm{COD})_{2}\right]$ as precursor and the IL $\left[\mathrm{CNC}_{3} \mathrm{MMIM}\right] \mathrm{NTf}_{2}$ (Table 1, entry 7). TEM analysis of the Ni-NPs embedded in IL shows well dispersed spherical shaped nanoparticles with a mean diameter of $7.8 \pm 1.1 \mathrm{~nm}$ (Fig. 1). In previous works, we reported the formation of $\mathrm{Ni}(0)$-NPs $(<10 \mathrm{~nm})$ and sponge-like agglomerates in [BMIM]NTf ${ }_{2}{ }^{25}$ This underlines again the beneficial effect of the nitrile moiety for a more defined synthesis. Other works reported the preparation of $\mathrm{Ni}$-NP systems in non-functionalised imidazolium based $\mathrm{NTf}_{2}$ ILs under hydrogen pressure with similar Ni(0)-NPs. ${ }^{29,30}$ It is well accepted that the IL acts as protective layer on the surface of the nanoparticles to inhibit further oxidation, ${ }^{23-25,29,31}$ this thin layer of IL around the NPs is also visible in the TEM images.

A partially oxidation of the surface can never be excluded in nanoparticles owing to the exposure to air of the robust catalyst system. ${ }^{29,30}$ In addition, it is known that NiO can be reduced to $\mathrm{Ni}(0)$ under hydrogenative conditions, therefore our results show that this perspective does not play such a crucial role in contrast to highly air sensitive Fe-NPs. ${ }^{27}$

We further examined the application of the optimized catalyst system to a broader substrate scope of terminal phenyl alkynes, aliphatic internal and terminal alkynes as well as functionalised alkynes (Table 2). Interestingly, with precise control of the reaction conditions, including time and hydrogen pressure, even terminal alkynes bearing a phenyl-moiety such as phenylacetylene and the methoxy-substituted 1-ethynyl-4-methoxybenzene can be hydrogenated to the corresponding olefins with high selectivity of $79-81 \%$ (Table 2, entries 1 and 3). Interestingly, $\mathrm{H}_{2}$ pressure variation showed that even pressures below 5 bar $\mathrm{H}_{2}$ are sufficient and beneficial for the selectivity of the partial hydrogenation (Table 2, entries 1 and 2 and Fig. 1, ESI $\dagger$ ). This makes this biphasic Ni-catalyst
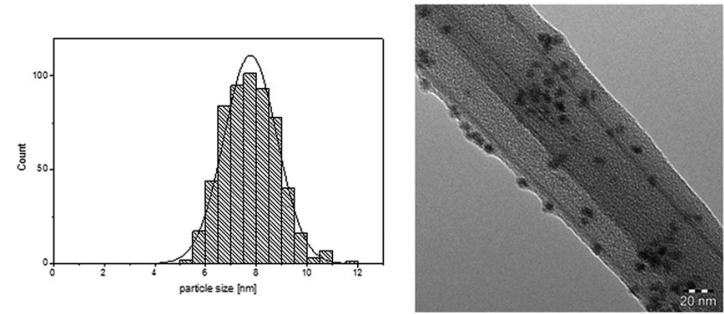

Fig. 1 Particle size distribution and TEM image of Ni-NPs dispersed in [CNC $_{3}$ MMIM]NTf $_{2}\left(38 \mu \mathrm{mol}\right.$ metal in $\left.0.15 \mathrm{~g} \mathrm{IL}, 70{ }^{\circ} \mathrm{C} ; 20 \mathrm{~h}\right)$.
Table 2 Substrate screening with Ni-NPs in $\left[\mathrm{CNC}_{3}{\mathrm{MMIM}] N T f_{2}}\right.$

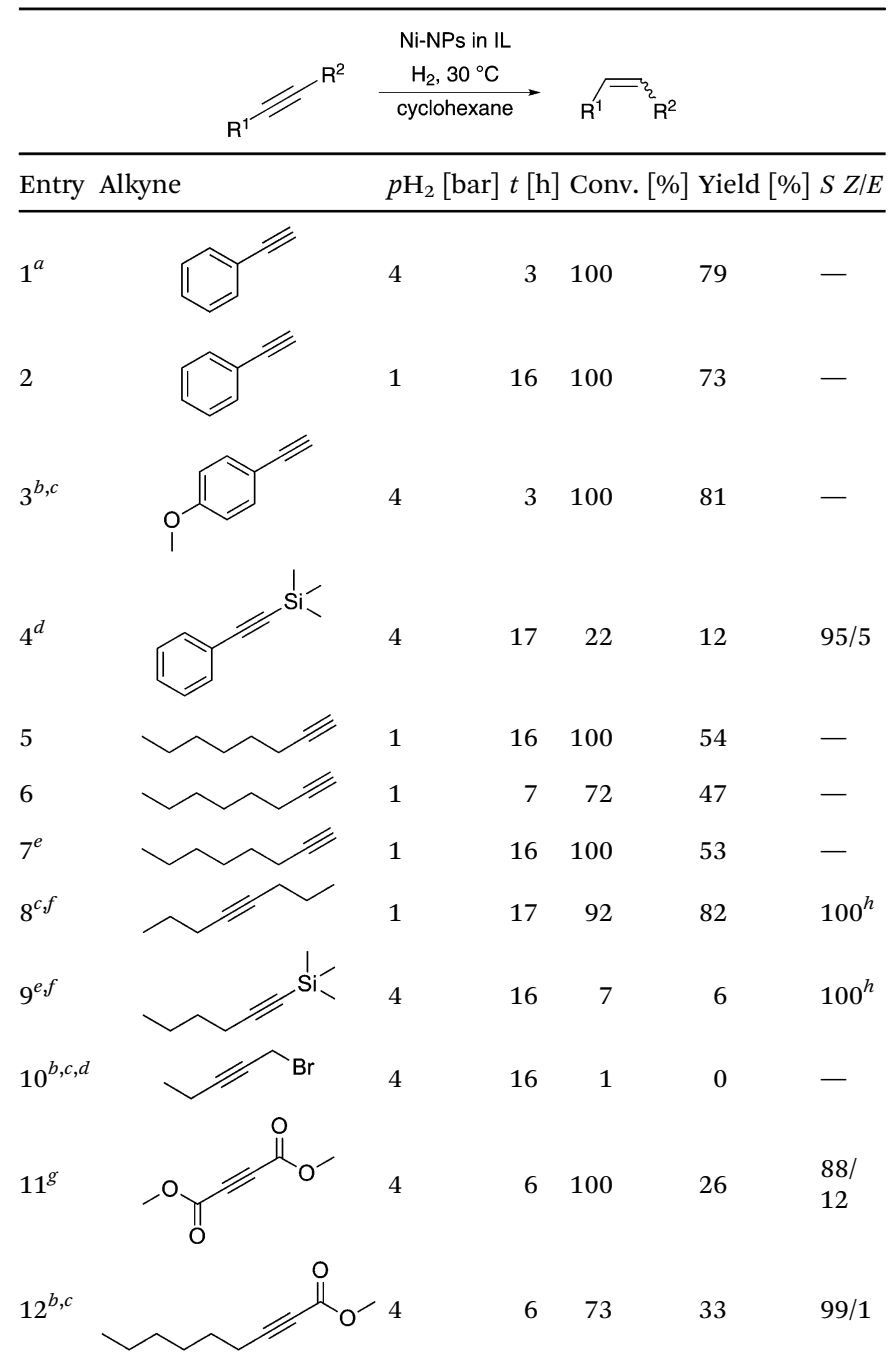

The volume of the co-solvent cyclohexane was $0.5 \mathrm{ml} .{ }^{a}$ Further experiments with the variation of the $\mathrm{H}_{2}$ pressure are shown in the ESI. ${ }^{b}$ Reactions were conducted in a scale of $0.38 \mathrm{mmol}$ substrate. ${ }^{c} \mathrm{An}$ external $\mathrm{H}_{2}$ reservoir was connected to the reactor. ${ }^{d}$ A reaction temp. of $50{ }^{\circ} \mathrm{C}$ was used. ${ }^{e}$ The reaction was conducted with a reduced catalyst loading with $1.8 \mathrm{mmol}$ substrate. ${ }^{f}$ A reaction temperature of $40{ }^{\circ} \mathrm{C}$ was used. ${ }^{g} \mathrm{~A}$ volume of $1 \mathrm{ml}$ of the co-solvent cyclohexane was used. ${ }^{h}$ According to NMR analysis.

system superior to known heterogeneous literature procedures with non-noble metals for the hydrogenation of terminal alkynes to the alkenes with molecular hydrogen. The phenylic and aliphatic internal alkynes bearing a trimethylsilyl group reacted poorly under similar reaction conditions (Table 2, entries 4 and 9). Even with a higher reaction temperature of $50{ }^{\circ} \mathrm{C}, 22 \%$ conversion of 1-phenyl-2-trimethylsilylacetylene yielded only $12 \%$ of the alkene (Table 2 , entry 4 ). The reaction might be hindered by the sterically bulky trialkylsilanes. However, aliphatic terminal alkynes like 1-octyne resulted in a mixture of alkene and alkane (Table 2, entries 5-7). Whilst the aliphatic internal alkyne 4-octyne required a higher reaction temperature of $40{ }^{\circ} \mathrm{C}$ for a high conversion of $92 \%$, this alkyne was selectively converted to the corresponding $(Z)$-alkene with $82 \%$ yield (Table 2 , entry 8 ). 


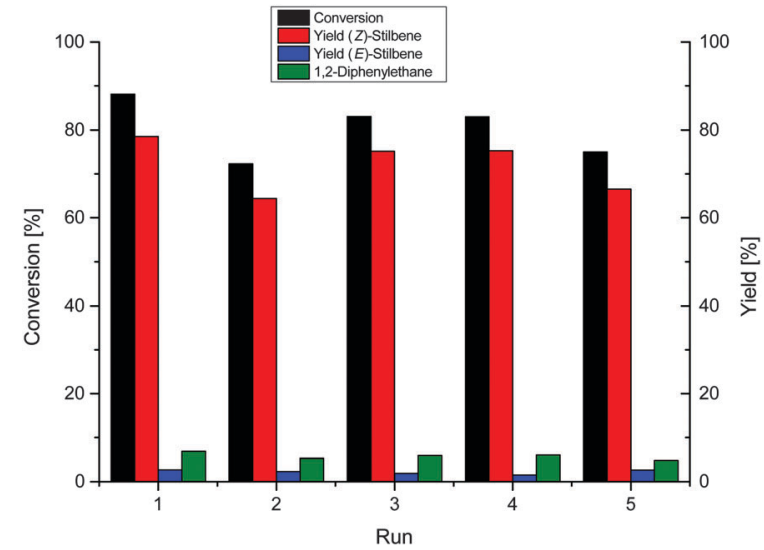

Fig. 2 Recycling experiment of the hydrogenation of diphenylacetylene over Ni-NPs in $\left[\mathrm{CNC}_{3} \mathrm{MMIM}_{\mathrm{NTT}}\right.$ at $40^{\circ} \mathrm{C}, 4$ bar $\mathrm{H}_{2}$ for $8 \mathrm{~h}$.

For the highly functional substrate dimethylacetylene dicarboxylate, the control of the chemoselectivity was difficult, as only $26 \%$ alkene were obtained after quantitative conversion of the starting material, the main product represents the overreduced alkane (Table 2, entry 11). The free electron pairs of the two methylester groups might additionally coordinate to the Ni-NPs and thus bring the alkyne/ alkene moiety to close vicinity to the surface of the nanoparticles and the active sites. Additionally, better solubility of the polar substrate in the ionic liquid is plausible which would increase the reactivity. A change to a substrate with only one methylester group and an alkyl chain alters the reactivity, resulting in a higher selectivity of $45 \%$ for the alkene (Table 2 , entry 12 ). For the terminal and internal aliphatic alkynes, no isomerisation products were detected by NMR-spectroscopy.

We tested the recycling of the NP-IL phase, using diphenylacetylene as the benchmark substrate, because a multiphase system allows for simple separation of product and catalyst phase, and enables easy handling and recycling of the NP-catalyst. ${ }^{27,33}$ After a reaction time of $8 \mathrm{~h}$, a conversion of $88.1 \%$ was achieved with $92 \%$ selectivity for the alkene (Fig. 2). The catalyst is highly durable as it was recycled over 5 runs without significant loss of selectivity and activity. The total TON for these recycling experiments is about 518 for the formation of stilbene.

To conclude, we developed a novel multiphase system with Ni-NPs as catalyst embedded in a nitrile-functionalised imidazolium based ionic liquid. The nitrile group is crucial for the selectivity of alkenes. This catalyst system shows high selectivity in the hydrogenation reaction of diphenylacetylene to the (Z)-alkene using very mild reaction conditions of $30{ }^{\circ} \mathrm{C}$ and 1-4 bar $\mathrm{H}_{2}$. Further studies examined that the method is also applicable to internal aliphatic alkynes as well as terminal phenylalkynes. Moreover, the catalyst is recyclable in multiphase systems with stable conversion rates and selectivity, and no precautions against moisture or air are required during the catalysis and the recycling of the active phase.

We gratefully acknowledge for financial support the Ministerium für Innovation, Wissenschaft und Forschung (NRW-returnee award 2009 for M. H. G. Prechtl), the Heisenberg-program (Deutsche Forschungsgemeinschaft), the Ernst-Haage Foundation (Max-Planck Institute for Chemical Energy Conversion) for the Ernst-Haage-Prize
2014, the Alexander-von-Humboldt Foundation (BRIGFOS Connect program) and $\mathrm{H}$. Konnerth acknowledges the Jürgen Manchot Stiftung for a research scholarship. S. Roitsch is acknowledged for TEM analysis. And we are grateful to H. G. Schmalz for access to GC analysis and for some alkynes.

\section{Notes and references}

1 M. Fouche, L. Rooney and A. G. M. Barrett, J. Org. Chem., 2012, 77, 3060-3070.

2 A. Furstner, O. Guth, A. Rumbo and G. Seidel, J. Am. Chem. Soc., 1999, 121, 11108-11113.

3 V. N. Odinokov, Chem. Nat. Compd., 2000, 36, 11-39.

4 R. Rossi, Synthesis, 1977, 817-836.

5 N. Y. U. Anisimova, M. V. Kiselevsky, A. V. Sosnov, S. V. Sadovnikov, I. N. Stankov and A. A. Gakh, Chem. Cent. J., 2011, 5, 88.

6 J. Leiro, J. A. Arranz, N. Fraiz, M. L. Sanmartin, E. Quezada and F. Orallo, Int. Immunopharmacol., 2005, 5, 393-406.

7 K. A. Roupe, J. A. Yanez, X. W. Teng and N. M. Davies, J. Pharm. Pharmacol., 2006, 58, 1443-1450.

8 H. Lindlar, Helv. Chim. Acta, 1952, 35, 446-456.

9 M. J. Maccarrone, C. R. Lederhos, G. Torres, C. Betti, F. ColomaPascual, M. E. Quiroga and J. C. Yori, Appl. Catal., A, 2012, 441, 90-98.

10 T. Mitsudome, Y. Takahashi, S. Ichikawa, T. Mizugaki, K. Jitsukawa and K. Kaneda, Angew. Chem., Int. Ed., 2013, 52, 1481-1485.

11 W. X. Niu, Y. J. Gao, W. Q. Zhang, N. Yan and X. M. Lu, Angew. Chem., Int. Ed., 2015, 54, 8271-8274.

12 R. Venkatesan, M. H. G. Prechtl, J. D. Scholten, R. P. Pezzi, G. Machado and J. Dupont, J. Mater. Chem., 2011, 21, 3030-3036.

13 M. Jacobson, M. Beroza and W. A. Jones, J. Am. Chem. Soc., 1961, 83, 4819-4824.

14 M. Yan, T. Jin, Y. Ishikawa, T. Minato, T. Fujita, L. Y. Chen, M. Bao, N. Asao, M. W. Chen and Y. Yamamoto, J. Am. Chem. Soc., 2012, 134, 17536-17542.

15 T. Q. Chen, J. Xiao, Y. B. Zhou, S. F. Yin and L. B. Han, J. Organomet. Chem., 2014, 749, 51-54.

16 E. Richmond and J. Moran, J. Org. Chem., 2015, 80, 6922-6929.

17 D. Savoia, E. Tagliavini, C. Trombini and A. Umanironchi, J. Org. Chem., 1981, 46, 5340-5343.

18 K. Schutte, A. Doddi, C. Kroll, H. Meyer, C. Wiktor, C. Gemel, G. van Tendeloo, R. A. Fischer and C. Janiak, Nanoscale, 2014, 6, 5532-5544.

19 B. Bridier, J. Perez-Ramirez, A. Knop-Gericke, R. Schlogl and D. Teschner, Chem. Sci., 2011, 2, 1379-1383.

20 F. Alonso, M. Osante and M. Yus, Adv. Synth. Catal., 2006, 348, 305-308.

21 S. Carenco, A. Leyva-Perez, P. Concepcion, C. Boissiere, N. Mezailles, C. Sanchez and A. Corma, Nano Today, 2012, 7, 21-28.

22 J. D. Scholten, B. C. Leal and J. Dupont, ACS Catal., 2012, 2, 184-200.

23 P. S. Campbell, M. H. G. Prechtl, C. C. Santini and P. H. Haumesser, Curr. Org. Chem., 2013, 17, 414-429.

24 M. H. G. Prechtl and P. S. Campbell, Nanotechnol. Rev., 2013, 2, 577-595.

25 M. H. G. Prechtl, P. S. Campbell, J. D. Scholten, G. B. Fraser, G. Machado, C. C. Santini, J. Dupont and Y. Chauvin, Nanoscale, 2010, 2, 2601-2606.

26 M. H. G. Prechtl, J. D. Scholten and J. Dupont, J. Mol. Catal. A: Chem., 2009, 313, 74-78.

27 T. N. Gieshoff, A. Welther, M. T. Kessler, M. H. G. Prechtl and A. J. von Wangelin, Chem. Commun., 2014, 50, 2261-2264.

28 W. Darwich, C. Gedig, H. Srour, C. C. Santini and M. H. G. Prechtl, RSC Adv., 2013, 3, 20324-20331.

29 P. Migowski, G. Machado, S. R. Texeira, M. C. M. Alves, J. Morais, A. Traverse and J. Dupont, Phys. Chem. Chem. Phys., 2007, 9, 4814-4821.

30 P. Migowski, S. R. Teixeira, G. Machado, M. C. M. Alves, J. Geshev and J. Dupont, J. Electron Spectrosc. Relat. Phenom., 2007, 156, 195-199.

31 J. Dupont and J. D. Scholten, Chem. Soc. Rev., 2010, 39, 1780-1804.

32 P. Migowski and J. Dupont, Chem. - Eur. J., 2007, 13, 32-39.

33 M. H. G. Prechtl, M. Scariot, J. D. Scholten, G. Machado, S. R. Teixeira and J. Dupont, Inorg. Chem., 2008, 47, 8995-9001. 